\title{
Study of Thyroid Function Abnormalities in Patients with Different Stages of Chronic Kidney Disease
}

Dr. Amar Prakash Arvind ${ }^{1 *}$, Dr. Jayachandra ${ }^{2}$, Dr. Riaz Ahmed ${ }^{1}$

\author{
${ }^{1} \mathrm{PG}$ in Internal Medicine, Bangalore Medical College and Research Institute, Fort, Krishna Rajendra Rd, Bengaluru, Karnataka 560002, India \\ ${ }^{2}$ Professor, Department of Medicine, Bangalore Medical College and Research Institute, Fort, Krishna Rajendra Rd, Bengaluru, Karnataka 560002, \\ India
}

DOI: $10.36347 /$ sasjm.2020.v06i03.003

| Received: 25.02.2020 | Accepted: 07.03.2020 | Published: 19.03.2020

*Corresponding author: Dr. Amar Prakash Arvind

There is lot of interaction between the kidney and thyroid gland during the disease States thyroid hormones have a major role in regulating the glomerular filtration rate through its hormonal actions in normal physiology. But these things are altered in the disease States such as chronic kidney disease. It is a well known fact that hypothyroidism causes decreased Glomerular filtration rate Whereas hyperthyroidism causes increased Glomerular filtration rate leading to renin-angiotensin-aldosterone system activation. In our study we aim to see the prevalence of low T3 syndrome in different stages of CKD which is a state of physiological benefit in preserving the proteins lost through the Kidneys in CKD patients and since CKD is progressed in hyperthyroidism state it is a protective mechanism in restoring the CKD status. Other subclinical hypothyroidism hyperthyroidism. Autoimmune hypothyroidism. Glomerulonephritis are all part of a dynamic endocrine and nephrology sequences. A Thorough knowledge of these is required for optimum treatment of thyroid in CKD patients.

Keywords: glomerular filtration rate, chronic kidney disease, thyroid stimulating hormone.

Copyright @ 2020: This is an open-access article distributed under the terms of the Creative Commons Attribution license which permits unrestricted use, distribution, and reproduction in any medium for non-commercial use (NonCommercial, or CC-BY-NC) provided the original author and source are credited.

\section{INTRODUCTION}

Chronic kidney disease is increasing in prevalence worldwide with irreversible loss of nephrons and metabolic, endocrine, secretory and excretory functions.${ }^{1}$ It affects every system in body including the thyroid hormone [2].

The reduced elimination of iodine in CKD, increases iodide levels thereby blocking thyroid hormone production (wolff chaikoff effect) [3]. Chronic Kidney Disease is associated with low levels of serum total and free T3, T4 and reverse T3 [4].

Thyroid Stimulating Hormone is usually normal and found to be in euthyroid state [5]. Many studies have reported hypothyroid, hyperthyroid and euthyroid states in Chronic Kidney Disease.

The relationship between severity of renal failure and thyroid dysfunction is unclear $[6,7]$.

The estimated prevalence of hypothyroidism in CKD is between 0-9\%. The low T3 syndrome in CKD is protective and promotes conservation of protien. The low T3 syndrome increases with severity of renal failure [8].

Our aim of the study was to study thyroid function abnormalities in patients with Chronic Kidney Disease and correlate them with severity of renal failure.

\section{CKD- CHRONIC KIDNEY DISEASE, TSH- THYROID STIMULATING HORMONE AIMS AND OBJECTIVES}

- To study thyroid function abnormalities in patients with Chronic Kidney Disease.

- To correlate thyroid function abnormalities with severity of renal failure.

- To differentiate primary hypothyroidism from thyroid dysfunction due to chronic kidney disease.

\section{MATERIALS AND METHODS}

The was a cross sectional observation study conducted in Department of Internal Medicine, BMC \& RI. included 50 CKD patients not on dialysis, who are only on conservative management. 


\section{Inclusion Criteria}

- Age more than 18 years.

- Patients with Chronic Kidney Disease on conservative management admitted in BMCRI.

- Patients with Chronic Kidney Disease who are willing to participate in the study and give informed written consent.

\section{Exclusion Criteria}

- Patients on Dialysis.

- Acute illness, diabetes mellitus, liver disease, recent surgery, trauma.

- Nephrotic range proteinuria or hypoalbuminemia.
- Patients who have received drugs altering thyroid profile like Amiodarone, Phenytoin, Beta blocker, Steroids, Estrogen, iodine compounds.

\section{STATISTICAL ANAL YSIS}

- Simple random sampling.

- $\mathrm{T}$ test was used for continuous variables and chi square test for categorical variables.

- ANOVA test was used to compare three groups.

- A p value of $<0.05$ was considered statistically significant.

\section{RESULTS}

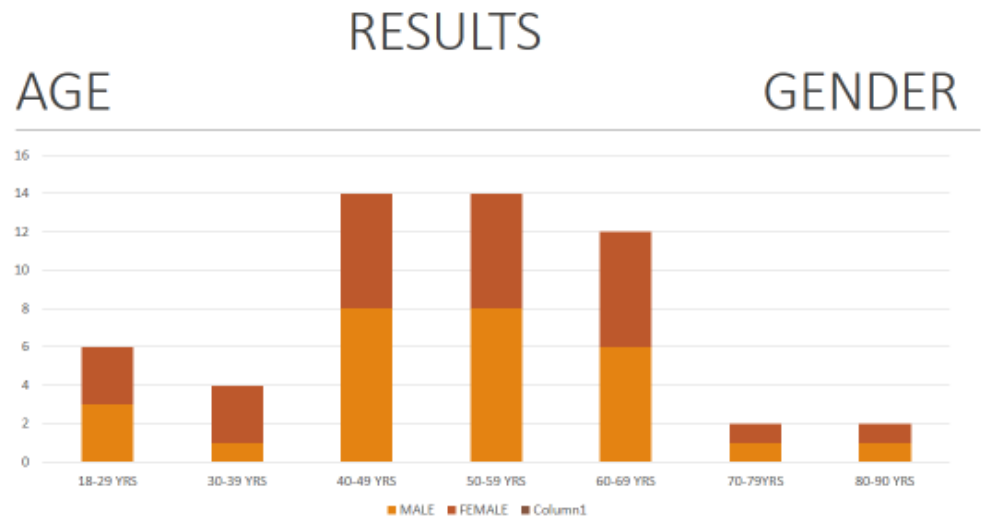

\section{Chart-1: Analysis of Age and Gender Distribution OF CKD}

In our study the age matched graph shows that maximum number of patients in the category of 40-49 years with 6 males and 4 females, 50- 59 years had 6 males and 4 females, whereas between 60 to 69 years there were 4 males and 4 females. The extreme age groups had few patients chronic kidney disease above 70 there were 2 females and 2 males between 18-29 years there were 2 males and 2 females and 30-39 years had 1 male and 2 females. There is a cluster of cases in middle age and with equal sex distribution.

\section{Number of Ckd patients with low T3}

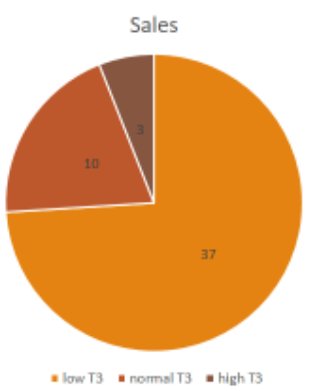

Chart-2: Pie Diagram Showing 
In our study the number of chronic kidney patients having low T3 were 37 which constitutes $74 \%$,the patients with normal $\mathrm{T} 3$ were 10 constituting
$20 \%$ and those with high T3 were 3, suggesting primary hyperthyroidism, so excluding them $75 \%$ of our patients had low T3 syndrome.

Table-1: Analysis of T3, T4, TSH

\begin{tabular}{|l|l|l|l|}
\hline Thyroid status & No of Patients with Normal value & Low value & High value \\
\hline T3 & 10 & 37 & 3 \\
\hline T4 & 26 & 24 & Nil \\
\hline TSH & 46 & Nil & 4 \\
\hline
\end{tabular}

In our study 37 patients had low T3, 24 had low T4 with 46 patients being normal TSH, only 4 had high high TSH. excluding patients with primary hypothyroidism.

\section{THYROID PROFILE IN DIFFERENT STAGES OF CKD}

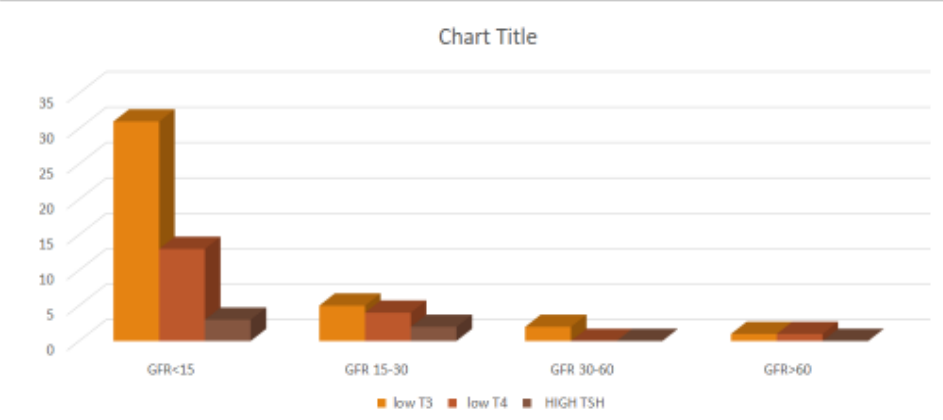

Chart-3: Bar Diagram

Patients with low T3 low T4 were clustered in more towards end stage renal disease with $60 \%$.

Patients also were in moderate number with low T3 and low T4 in stage 4 chronic kidney disease. $20 \%$
In stage 3 chronic kidney disease T4 and TSH were almost normal with only $10 \%$ patients had low T3 syndrome.

In stage 2 chronic kidney disease $10 \%$ had low T3, low T4 with rest being normal TSH.

Table-3: Incidence of low T3 syndrome in CKD

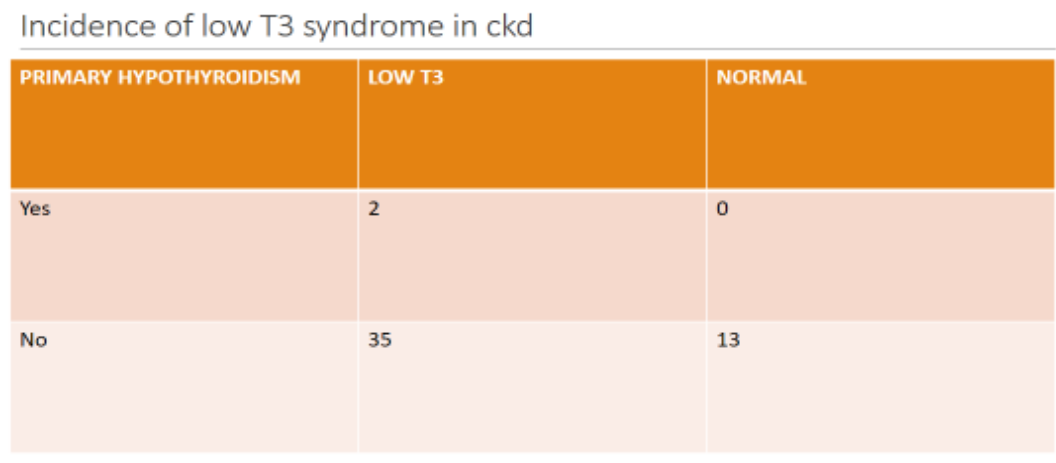

In our study patients with low T3 were 35 accounts for nearly $70 \%$ and T3 were 13 (26\%). Only 2 patients had primary hypothyroidism- $4 \%$ 
Table-4: Statistical Analysis

\section{Correlation of thyroid function with severity of renal failure}

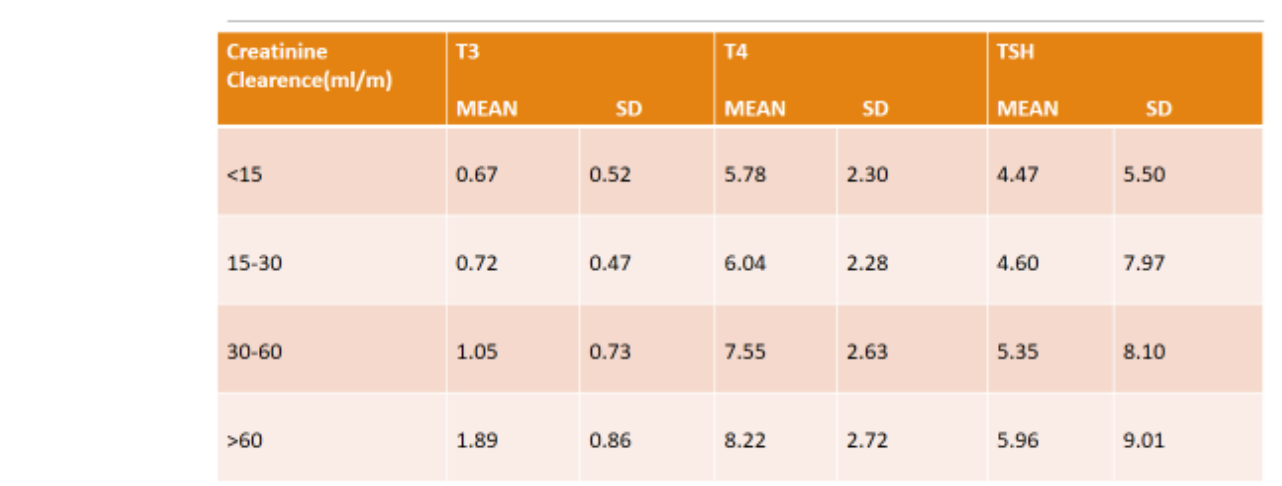

In our study low T3 syndrome had ranged from $0.67-1.89$ of the mean with a standard deviation of 0.52-0.86.

\section{DISCUSSION}

The present study was aimed to assess the prevalence of thyroid dysfunction in chronic kidney disease patients and to determine the correlation between thyroid dysfunction and severity of renal disease. Various studies was conducted about thyroid dysfunction and severity of Chronic kidney disease and has shown different results.

Since thyroid profile undergoes changes due to dialysis [10]. In our study, chronic kidney disease patients only on conservative management were studied. Dialysis also changes the previous serum thyroid hormone status in patients with renal failure several studies have observed a link between CKD and hypothyroidism [12]. But there are not many studies correlating low $\mathrm{T} 3$ with severity or stage of CKD. In our study none of the patients had clinical or biochemical features Hyperthyroidism.

In our study 50 patients of CKD who were on conservative management fulfilling the criteria for Chronic kidney disease, the maximum number of patients were in the category of 40-49 years with 6 males and 4 females, 50- 59 years had 6 males and 4 females, whereas between 60 to 69 years there were 4 males and 4 females. The extreme age groups had few patients chronic kidney disease above 70 there were 2 females and 2 males between 18-29 years there were 2males and 2 females and 30-39 years had 1 male and 2 females. There was a cluster of cases in middle age and with equal sex distribution. Among the 50 patients study, $60 \%$ of patients were males and $30 \%$ patients were females.

In our study the duration of symptoms of CKD varied from 4 months to 8 months, mean duration being 6.07 months and the creatinine clearance varied from 4 $\mathrm{ml} /$ minute- $60 \mathrm{ml} /$ minute.
Of the 50 patients, 38 patients had GFR of less than $15 \mathrm{ml} /$ minute accounting to $76 \%, 6$ patients had GFR ranging from $15-30 \mathrm{ml} /$ minute accounting for $12 \%$ and 4 patients had GFR ranging from 30 $60 \mathrm{ml} / \mathrm{minute}$ accounting for $8 \%$.and $4 \%$ above $60 \mathrm{ml} / \mathrm{min}$. Among these patients most were in the range of creatinine clearance $<15 \mathrm{ml} /$ minute. Among these patients, blood urea was in the range of $80-140 \mathrm{mg} / \mathrm{dl}$, and creatinine values varied from $2.4-17 \mathrm{mg} / \mathrm{dl}$, the mean value being 8.67 .

Serum calcium values were found to be low in 40 patients accounting for $80 \%$, normal in 10 patients accounting for $20 \%$.

Serum phosphorus values were high in 20 patients accounting for $40 \%$ and the remaining 30 patients were found to be in normal range accounting for $60 \%$.

24 hours urinary protein excretion was < $1 \mathrm{~g}$ /day in all the patients in our study. ultrasound abdomen was done in all patients, that showed features of contracted kidney in 40 patients accounting for $80 \%$ and the remaining 10 patients had loss of corticomedullary differentiation, accounting for $20 \%$.

Out of 50 patients in our study, 48 patients had anaemia, 44 patients had normocytic normochromic anaemia in peripheral blood picture and the remaining 4 patients had microcytic hypochromic anaemia.

The only Indian study directly correlating severity of CKD and Low T3 syndrome is by swaminathan $\mathrm{K}$ et al., who compared the estimated Glomerular filtration rate values with , T3,T4,TSH found a significant correlation with $66 \%$ patients having thyroid dysfunction with $>50 \%$ having low $\mathrm{T} 3$, more severe the stage of chronic kidney disease [13-15]. 


\section{OTHER STUDIES}

- Michael Chonchol et al., found that subclinical primary hypothyroidism is a relatively common condition (18\%) among persons with $\mathrm{CKD}$ not requiring chronic dialysis, and is independently associated with progressively lower estimated GFR.

- German Ramirez et al., found that thyroid hypofunction is a direct result of renal failure and serum levels of thyroxine and triiodothyronine fall progressively as renal function worsens, suggesting the severity and duration of the uremic state is a major influence on hormone synthesis.

- Mohammed et al., found that the prevalence of subclinical hypothyroidism increases consistently in patients who have a decline in GFR.

\section{LIMITATIONS OF OUR STUDY}

- This study directly correlating low T3 syndrome and stage of chronic kidney disease.

- Our study also showed a strong positive correlation between low T3 and End stage renal disease.

- However in this study the different etiologies, in patients of CKD was not assessed.

\section{CONCLUSION}

- In our study of 50 CKD patients, $60 \%$ had low T3 values.

- Excluding hypothyroidism the T3 level was low in 50\% patients and T4 level was low in $20 \%$ patients

- The change in serum T3 and T4 can be taken as protective to conserve protein.

- As the stage of CKD increases the patients with low T3 T4 level increases.

- The incidence of low T3 increases with age.

- There is a direct linear relationship with GFR and low T3 in our patients.

Funding: None

Conflict of Interest: None Declared

Ethical Approval: Not Required

\section{REFERENCES}

1. Joanne MB, Karl SK. Chronic kidney disease. In: Dan LL, Anthony SF, Dennis K. Harrison's Principles of Internal Medicine, Vol. 2, 18th edn., McGraw Hill, USA, 2011;2289-2293.

2. Jabbar Z, Aggarwal PK, Chandel N, Kohli HS, Gupta KL, Sakhuja V, Jha V. High prevalence of vitamin D deficiency in north Indian adults is exacerbated in those with chronic kidney disease. Nephrology. 2009 Apr;14(3):345-9.
3. Robert WS. Abnormalities in the thyroid gland and hypothalamo pituitary thyroid axis in patients with CKD Diseases of the kidney and urinary tract, eighth edition, 2007; 3:2518.

4. Kaptein EM, Quion-Verde H, Massry SG. Hemodynamic effects of thyroid hormone. Contributions to Nephrology, 1984.

5. Mohamedali M, Reddy Maddika S, Vyas A, Iyer V, Cheriyath P. Thyroid disorders and chronic kidney disease. International journal of nephrology. 2014;2014,14:1-6.

6. Levey AS, Coresh J, Balk E, Kausz AT, Levin A, Steffes MW, Hogg RJ, Perrone RD, Lau J, Eknoyan G. National Kidney Foundation practice guidelines for chronic kidney disease: evaluation, classification, and stratification. Annals of internal medicine. 2003 Jul 15;139(2):137-47.

7. Feinstein EI, Kaptein EM, Nicoloff JT, Massry SG. Thyroid function in patients with nephrotic syndrome and normal renal function. American journal of nephrology. 1982;2(2):70-6.

8. Dudani RA. Thyroid dysfunction in Ureaemia, Journal Assoc Physicians India, 1981;29: 1037-40.

9. Quionverde H, Kaptein EM, Rodriguez H, Massry $\mathrm{S}$. Prevalence of thyroid-disease in chronic-renalfailure (CRF) and dialysis patients. InKIDNEY INTERNATIONAL 1984 Jan 1 (Vol. 25, No. 1, pp. 190-190). 350 MAIN ST, MALDEN, MA 02148: BLACKWELL SCIENCE INC.

10. Joseph LJ, Desai KB, Mehta HJ, Mehta MN, Almeida AF, Acharya VN, Samuel AM. Measurement of serum thyrotropin levels using sensitive immunoradiometricassays in patients with chronic renal failure: alterations suggesting an intact pituitary thyroid axis. Thyroidology. 1993 Aug;5(2):35-9.

11. KarunanidhiA et al. Thyroid function in patients with chronic renal failure. Indian J Med Research, 1979; 69: 792-7.

12. Hardy MJ, Ragbeer SS, Nascimento L. Pituitarythyroid function in chronic renal failure assessed by a highly sensitive thyrotropin assay. The Journal of Clinical Endocrinology \& Metabolism. 1988 Jan 1;66(1):233-6.

13. Hegedüs L, Andersen JR, Poulsen LR, Perrild H, Holm B, Gundtoft E, Hansen JM. Thyroid gland volume and serum concentrations of thyroid hormones in chronic renal failure. Nephron. 1985;40(2):171-4.

14. Iglesias P, Diez JJ. Thyroid dysfunction and kidney disease. European journal of endocrinology. 2009 Apr 1;160(4):503-15.

15. Couser WG, Remuzzi G, Mendis S, Tonelli M. The contribution of chronic kidney disease to the global burden of major noncommunicable diseases. Kidney international. 2011 Dec 2;80(12):1258-70. 